\title{
Pelvis-shoulder dysplasia
}

INSERM

\section{Source}

INSERM. (1999). Orphanet: an online rare disease and orphan drug data base. Pelvisshoulder dysplasia. ORPHA:2839

Pelvis-shoulder dysplasia is a rare focal skeletal dysostosis characterized by symmetrical hypoplasia of the scapulae and the iliac wings of the pelvis. 